\title{
CONSERVAÇÃO PÓS-COLHEITA DE ABACAXI 'PÉROLA' PRODUZIDO EM SISTEMAS CONVENCIONAL E INTEGRADO ${ }^{1}$
}

\author{
LAESIO PEREIRA MARTINS², SILVANDA DE MELO SILVA³, \\ ALEXANDRE PAIVA DA SILVA ${ }^{4}$, GETÚLIO AUGUSTO PINTO DA CUNHA 5 , \\ REJANE MARIA NUNES MENDONÇA², LEÔNCIO DA COSTA VILAR ${ }^{5}$, \\ JAMIR MASCENA ${ }^{6}$, JOSÉ TEOTÔNIO LACERDA
}

RESUMO - O objetivo deste trabalho foi avaliar a conservação pós-colheita de abacaxi ‘Pérola' proveniente de produção convencional e integrada. Os abacaxis foram colhidos no ponto de maturidade comercial, de plantios conduzidos sob os sistemas de produção integrada (PI) ou convencional (PC), localizados no município de Santa Rita-PB. Esses frutos foram armazenados sob condição ambiente ( $\left.23{ }^{\circ} \mathrm{C}, 65 \% \mathrm{UR}\right)$, durante 30 dias. $\mathrm{O}$ experimento foi conduzido em delineamento inteiramente casualizado, em fatorial 2x7 (sistemas de produção x períodos de análises), com quatro repetições. Frutos da PI apresentaram menor taxa de senescência, menor translucidez e melhor aparência. Abacaxi 'Perola' oriundo do sistema PI apresentou vida útil pós-colheita de 25 dias, com 5 dias de aumento comparado a frutos da PC no armazenamento sob a condição ambiente .

Termo para Indexação: Ananas comosus comosus, armazenamento, podridão, translucidez.

\section{POSTHARVEST CONSERVATION OF 'PEROLA' PINEAPPLE PRODUCED IN CONVENTIONAL AND INTEGRATED SYSTEMS}

\begin{abstract}
The objective of this study was to evaluate the postharvest conservation of 'Perola' pineapple from conventional and integrated productions. Pineapples were harvested at commercial maturity point, from integrated (IP) and conventional (CP) production systems located at the municipality of Santa Rita-PB, Brazil. These fruits were stored under room conditions $\left(23^{\circ} \mathrm{C}, 65 \mathrm{RH}\right)$, during 30 days. The experiment was carried out on a completely randomized design, in factorial 2x7 (production systems $\mathrm{x}$ evaluation periods), with four replications. Fruits from IP presented lower senescence rate and translucency, and better appearance. 'Pérola' pineapple from IP system presented 25 days of postharvest life, with a five-day increase compared with fruits from $\mathrm{CP}$ at storage under room conditions.
\end{abstract}

Index terms: Ananas comosus comosus, storage, decay, translucency.

\section{INTRODUÇÃO}

O abacaxi representa o segmento frutícola de maior importância no Estado da Paraíba, atualmente o segundo maior produtor brasileiro, que em 2010 produziu 273,91 milhões de frutos (IBGE, 2012). O abacaxi é cultivado em 37 municípios Paraibanos, destacando-se como principais produtores: Santa Rita, Itapororoca, Araçagi e Pedras de Fogo. Além da quantidade produzida e da produtividade mais elevada (29,5 t/ha em relação à média nacional de 25,1 t/ha), o Estado destaca-se também pela qualidade do fruto, reconhecida nacionalmente (FRUTAS DOCE MEL, 2009), em função do bom nível tecnológico empregado e das condições ambientais favoráveis, sendo a cultivar Pérola a mais plantada (RODRIGUES et al., 2010).

O abacaxi 'Pérola’ é muito apreciado no mercado interno pela sua polpa suculenta e saborosa, considerada insuperável para o consumo fresco, e com grande potencial de comercialização internacional, pois é apreciado no Mercosul e na Europa (CUNHA, 2006). Seu potencial para exportação mostra a necessidade de se estabelecer sistemas de produção para

${ }^{1}$ (Trabalho 001-12). Recebido em: 02-01-2012. Aceito para publicação em: 27-06-2012.

${ }^{2}$ Estudante de Doutorado em Agronomia/Programa de Pós-Graduação em Agronomia-UFPB. E-mail: martins-lp@hotmail.com ${ }^{3}$ Prof. Ph.D., Lab. Biologia e Tec. Pós-Colheita, DCFS/CCA/UFPB, -Areia - PB. E-mails: silvasil@cca.ufpb.br - autor correspondente; rejane@cca.ufpb.br

${ }^{4}$ Prof. D.Sc., UACTA/UFCG, Pombal -PB, E-mail: paivadasilva@gmail.com;

${ }^{5}$ Pesq. Embrapa Mandioca e Fruticultura, Cruz das Almas, BA, E-mail: gapcunha@hotmail.com;

${ }^{6}$ Extensionista, Agr., EMATER-PB, João Pessoa-PB, E-mail: comosus@terra.com.br;

${ }^{7}$ Fiscal da Defesa Agropecuária, Agr., MAPA, SFA-PB, João Pessoa-PB, E-mail: jamir.sousa@agricultura.gov.br 
a obtenção de frutas com qualidade maximizada, de modo a atender ás atuais exigências de padrões. Isto permitirá competir com os demais países exportadores e atender aos mercados consumidores, cada vez mais exigentes quanto à qualidade e segurança do produto, bem como às normas ambientais e sociais (MATTOS et al., 2009; SILVA et al., 2010), sendo a percepção dessas novas demandas fundamental para os produtores permanecerem ou alcançarem esses mercados (FORNAZIER; WAQUIL, 2012).

Neste contexto, a Produção Integrada de Frutas (PIF) emprega parâmetros que permitem aferir a qualidade das frutas, do solo, do ambiente, das condições de trabalho e das alterações na fisiologia das plantas, com obtenção de frutos com alta qualidade (ANDRADE et al., 2008), minimizando o uso de agroquímicos e preservando o meio ambiente, assim como a saúde do consumidor e do produtor (BECKER et al., 2011). No Brasil, a PIF já está sedimentada para frutos de caroço, embora sua apropriação tecnológica não seja massiva (SILVA et al., 2011). No contexto internacional, este já é um sistema compulsório (CHEVRIN, 2002). Neste sentido, a PI foi implantada na abacaxicultura do Estado da Paraíba, em 2005, visando a tornar a fruta mais competitiva em termos de qualidade para os mercados nacional e internacional (CUNHA, 2006).

O estudo da conservação pós-colheita de abacaxis oriundos de diferentes sistemas de produção se faz necessário para sua validação, permitindo impulsionar o agronegócio, seja pela possibilidade de abastecimento das diferentes regiões brasileiras, seja para incrementar a exportação de frutas frescas. Neste contexto, o objetivo deste trabalho foi comparar frutas oriundas da produção convencionalmente utilizada pelo produtor, com as da produção integrada, em relação à sua conservação pós-colheita sob condições ambientes.

\section{MATERIAL E MÉTODOS}

O experimento foi realizado no Laboratório de Biologia e Tecnologia Pós-Colheita do Centro de Ciências Agrárias da Universidade Federal da Paraíba. O abacaxi ‘Pérola' foi proveniente de propriedade rural do município de Santa Rita-PB, da safra de 2007/2008. Dois plantios, de aproximadamente um hectare cada, distanciados entre si de cerca de $300 \mathrm{~m}$, foram conduzidos obedecendo ao preconizado pelos sistemas de Produção Integrada (PI) e Convencional (PC). A colheita sob Boas Práticas Agrícolas (SILVA et al., 2010) foi realizada aleatoriamente, na parte central de cada plantio, e constou de quatro fileiras de 75 plantas, separadas entre si por duas fileiras de plantas. Na PC, prevaleceu o manejo e práticas culturais normalmente utilizadas pelos produtores, e na PI foram aplicadas as práticas recomendadas nas Normas de Produção Integrada de Abacaxi (PIA, 2008), nas quais prevalecem o manejo do solo com cobertura vegetal, roçadas nas entrelinhas, adubação das plantas com base na análise do solo e análise foliar, respeitando os limites máximos de fertilizantes químicos, principalmente os nitrogenados, e o monitoramento da flutuação de ataque de pragas, que serviu como indicativo para o nível de controle. Estes plantios foram acompanhados durante os 18 meses do ciclo da cultura, e os abacaxis, colhidos na maturidade comercial (frutilhos apresentando coloração verde em toda a extensão do fruto), sendo classificados como no estádio de maturação 'verdoso’ (CEAGESP, 2003). No laboratório, os frutos foram selecionados quanto à uniformidade de massa e maturação, e ausência de danos mecânicos e/ou fitopatológicos, antes de serem armazenados sob condições de ambiente $\left(23 \pm 2{ }^{\circ} \mathrm{C}, 65 \pm 5 \% \mathrm{UR}\right)$, com avaliações aos 0;5;10; 15;20; 25 e 30 dias, quanto a:

Perda de massa (\%), calculada tomando-se como referência o peso inicial dos frutos, para cada período de análise, usando-se balança semianalítica; Firmeza do fruto com casca $(\mathrm{N})$ - determinada individualmente em dois pontos distintos da região mediana dos frutos íntegros, com penetrômetro Magness Taylor Pressure Tester (Drill Press Stand, Canada), com ponta de 2/16 polegadas, inserção de 6 mm; Sólidos solúveis (\%) - este teor foi determinado com refratômetro digital (Kruss-Optronic, Hamburgo, Alemanha), segundo a AOAC (2005); Acidez titulável (\% ác.cítrico) - determinada por titulação do suco com solução de $\mathrm{NaOH}$ a 0,1M (IAL, 2005); Relação SS/AT - relação entre os teores de sólidos solúveis e de acidez titulável; $\mathbf{p H}$ - determinado no suco,utilizando-se de potenciômetro digital (Hanna, Singapura), conforme a AOAC (2005); Ácido ascórbico (mg $100^{-1} \mathrm{~g}$ de polpa) - doseado por titulometria com solução de 2,6 diclo-fenol-indofenol a 0,02 \% (AOAC, 2005) e Açúcares redutores e não redutores (g $100^{-1} \mathrm{~g}$ de polpa) cujos teores foram determinados de acordo com o IAL (2005). A coloração da casca e da polpa foi medida com colorímetro Minolta CR 300, nos atributos, $L^{*}$ (luminosidade), $a^{*}, b^{*} \mathrm{e}$ ângulo de cor $\left(H^{\circ}\right)$, sendo realizadas seis leituras da base para o ápice de cada fruta.

Os abacaxis foram avaliados quanto á cor por 9 avaliadores treinados, utilizando escalas subjetivas (DANTAS Jr. et al., 2009). Cor do fruto - 1= frutilhos totalmente verdes; $2=$ início da coloração amarela no centro dos frutilhos, em mais de 50\% 
da infrutenscência; 3=100\% da infrutescência com frutilhos amarelos no centro; $4=50 \%$ dos frutilhos amarelos; $5=100 \%$ dos frutilhos amarelos; e $6=$ todo o fruto amarelo. Senescência - Determinada mediante o aparecimento de sintomas de infestação fúngica, podridões e exsudação, segundo uma escala subjetiva, em que: $1=$ sem infestação, $0 \% ; 2=1$ a 5\% de ocorrência; 3= 6 a 15\%; 4= 16 a 30\%; $5=31$ a 45\%; 6= 46 a 60\%; 7= 61 a 75\%; e 8=> 75\% de lesões devidas a podridões e exsudação (DANTAS Jr. et al., 2009). Translucência - 1= Polpa completamente opaca; $2=$ polpa com até $10 \%$ de área translúcida; 3= polpa com $11 \%$ a $25 \%$ de área translúcida; $4=26 \%$ a 50\% de área translúcida; 5= polpa com 51\% a 75\% de área translúcida, e 6= com mais de 75\% de área translúcida (SANTOS, 2006); Aparência geral - 1= perda completa da turgidez, do brilho e da cor, superfície murcha, desenvolvimento de fungos, exsudação da polpa, senescência avançada, imprestável para o consumo; $3=$ murchamento acentuado, sem brilho aparente e perda total do aroma, presença de manchas externas, sintomas de senescência e/ou podridão; $5=$ pouco frescor, ligeira perda da turgidez, perda de brilho, aparência ligeiramente atrativa, ausência de doenças, manchas externas e/ou podridão; $7=$ fruto fresco, túrgido, superfície com pouco brilho, ausência de manchas externas ou doenças; $9=$ fruto fresco, túrgido, superfície brilhante, saudável, atrativa, isento de podridão (SANTOS, 2006).

O delineamento experimental foi o inteiramente casualizado, sendo avaliados dois sistemas de produção (PI e PC) e sete períodos de armazenamento, em quatro repetições de quatro abacaxis. Os resultados foram submetidos à ANOVA, avaliando-se a significância pelo teste $\mathrm{F}$, a $5 \%$ de probabilidade, determinado as curvas e equações de regressão, com os respectivos coeficientes.

\section{RESULTADOS E DISCUSSÃO}

A perda de massa pelos frutos dos dois tratamentos não mostrou diferenças $(p<0,05)$, como para pêssegos oriundos da produção convencional (PC) e integrada (PI) (SEIBERT et al., 2007), mas aumentou de forma linear durante o armazenamento (Figura $1 \mathrm{~A}$ ), sendo superior a $12 \%$, após 15 dias ao ambiente. A perda de massa em abacaxi é, em parte, ocasionada pela perda de turgescência (DANTAS Jr. et al., 2009), que é devida á diferença de pressão de vapor entre o fruto e o ambiente (PALIYATH et al., 2008).

A firmeza inicial foi de 80,54 $\mathrm{N}$ e 79,90 $\mathrm{N}$ e declinou para 13,05 $\mathrm{N}$ e 11,87 $\mathrm{N}$, nas frutas dos sistemas PI e PC, respectivamente, após 15 dias de armazenamento sob condições ambientes (Figura 1B).
Isto acontece na maioria dos frutos, com o avanço da maturação (CHITARRA; CHITARRA, 2005), sendo o declínio da firmeza relacionado à perda da integridade dos polímeros da parede celular, que durante a maturação sofrem transformações, levando à perda de estrutura e, em consequência, ao amaciamento da textura do fruto pela atividade das enzimas da parede celular, tais como a pectinametilesterase e a poligalacturonase (PALIYATH et al., 2008). Seibert et al. (2007), em três safras consecutivas de pêssegos, verificaram maior firmeza em frutos da PI nos dois primeiros anos, mas no terceiro ano a firmeza não diferiu entre PC e PI.

O $L^{*}$ (brilho) da casca aumentou mais lentamente durante o armazenamento para frutos da PI até o $15^{\circ}$ dia, refletindo em menor brilho superficial dos frutos até esse ponto, evoluindo de modo similar em seguida (Figura 2A). Os parâmetros a* e b* da casca (Figuras 2B e 2C) de abacaxis dos dois sistemas de produção aumentaram até 25 dias de armazenamento seguido de declínio. Isso indica a transição da coloração verde para a amarela da casca. Paralelamente, observou-se declínio acentuado de $H^{\circ}$, para PC e PI, menos acentuado para abacaxis da PI entre o $5^{\circ}$ e o $25^{\circ}$ dia (Figura 2D), refletindo a mudança na tonalidade de cor verde para amarela durante o armazenamento de abacaxi ao ambiente.

Para a coloração da polpa, o $L^{*}$ aumentou gradativamente durante o armazenamento, principalmente para os abacaxis do sistema PI, cuja polpa apresentava mais brilho (Figura 3A). O parâmetro $a^{*}$ da polpa (Figura 3B) aumentou durante o armazenamento para ambos os sistemas de produção, cuja transição da cor verde para a amarela (mudança de $-a^{*}$ para $+a^{*}$ ) ocorreu entre o dia 15 e o dia 20 enquanto $b^{*}$ aumentou a partir do $20^{\circ}$ dia (Figura 3C), indicando a completa mudança da cor verde para a amarela, como indicativo de que a síntese de carotenoides na polpa do abacaxi é resultado da maturação (CARVALHO, 1999). Paralelamente, o $H^{\circ}$ aumentou até o $20^{\circ}$ dia de armazenamento, diminuindo a partir desse ponto, refletindo na tonalidade amarela. Entretanto, os valores de $H^{\circ}$ foram mais elevados para abacaxi da PI, podendo ser um indicativo de algum retardo no desenvolvimento da cor e, portanto, da maturação nesses frutos.

Os teores de SS atingiram valor máximo de $12,23 \%$ no $15^{\circ}$ dia para abacaxi da PC, e $12,53 \%$ no $20^{\circ}$ de armazenamento para abacaxi da PI (Figura 4A), provavelmente em decorrência de uma redução na taxa metabólica pós-colheita em frutas da PI.

A acidez titulável (AT) aumentou durante o armazenamento de abacaxis ao ambiente, indistintamente do sistema de produção (Figura 4B). Segundo 
Carvalho (1999), a acidez do abacaxi ‘Pérola’ pode variar de 0,6 a 1,6\% de ácido cítrico, na faixa dos valores obtidos neste experimento para ambos os sistemas de produção. Na maioria dos frutos, a acidez representa um dos principais componentes do sabor, no entanto a aceitação do fruto depende do balanço entre ácidos e açúcares (CHITARRA; CHITARRA, 2005), sendo que, para o abacaxi, a preferência incide sobre os altos teores de acidez (CARVALHO, 1999).

A relação SS/AT diminuiu durante o armazenamento, e abacaxis da PC apresentaram maiores valores, indicando serem mais saborosos quando comparados aos da PI até o $15^{\circ}$ dia (Figura 4C). Segundo Chitarra e Chitarra (2005), a relação SS/ AT é utilizada para avaliar o grau de maturação e, portanto, o sabor da maioria dos frutos e quando avaliada durante o armazenamento, auxilia na compreensão dos processos metabólicos em progresso, podendo também indicar menor taxa metabólica dos frutos da PI.

O teor de ácido ascórbico em abacaxis de ambos os sistemas de produção (Figura 4D) diminuiu durante o armazenamento, sendo inferior nos da PI. Entre outros fatores, o teor de ácido ascórbico depende dos tratos culturais, bem como das condições de armazenamento (PALIYATH et al., 2008), podendo ter sido afetado pelos sistemas de produção adotados.

Os açúcares redutores de abacaxis dos sistemas de produção diminuíram até o $25^{\circ}$ dia de armazenamento, pelo consumo na oxidação respiratória (PAULL; CHEN, 2003), aumentando em seguida, sobretudo nos da PC (Figura 5A). Por sua vez, os açúcares não redutores aumentaram a partir do $10^{\circ}$ dia de armazenamento (Figura 5B). A maioria dos frutos apresenta maior doçura com o avanço da maturação devida ao aumento dos açúcares solúveis, através de suas interconvenções, ou como resultado da concentração de sólidos, ocasionado pela perda de massa durante o armazenamento (PALIYATH et al., 2008) .

A coloração amarela da casca de abacaxi 'Pérola', oriundo da PI, evoluiu mais lentamente durante o armazenamento, corroborando valores mais elevados do $H^{\circ}$. Abacaxis da PC estavam com os frutilhos amarelos no $10^{\circ}$ dia, enquanto nos da PI, esta coloração foi atingida no $18^{\circ}$ dia (Figura 6A). A evolução da cor da casca em abacaxi é decorrente da degradação da clorofila, o que revela os carotenoides, que passam a se sobressair (PAULL; CHEN, 2003). No contexto da produção integrada de abacaxi, o manejo mais sustentável adotado pode ter ocasionado um retardo na degradação da clorofila.
Os sintomas de senescência aumentaram durante o armazenamento, em taxas muito inferiores em abacaxis da PI (Figura 6B). Abacaxis da PC, a partir do $10^{\circ}$ dia, apresentavam sintomas de senescência entre 16 e $30 \%$ (nota 4), enquanto nas frutas da PI, no mesmo período, este índice era inferior a 5\% (nota 2). Adicionalmente, abacaxis da PI apresentaram menores incidências de podridões, como também reportado para pêssego da PI por Seibert et al. (2007). Produto minimamente processado de abacaxi ‘Perola' cultivado sob Boas Práticas Agrícolas (BPA) apresentou superior qualidade microbiológica (SILVA et al., 2010), indicando ser a BPA utilizada na PI necessária para produção segura (MATOS et al., 2009) e competitiva (FORNAZIER; WAQUIL, 2012) para a abacaxicultura.

A translucidez de abacaxis dos dois sistemas de produção aumentou durante o armazenamento. Entretanto, em abacaxis da PC, já no $20^{\circ}$ dia, a área afetada pela translucidez era superior a $50 \%$, enquanto nos da PI este nível foi atingido no $30^{\circ}$ dia (Figura 6C), indicando que a utilização racional de insumos pode auxiliar na manutenção da integridade da parede celular (PAULL; CHEN, 2003), reduzindo a incidência desta desordem.

A aparência foi superior em abacaxis da PI. Com base no limite de aceitação estabelecido (nota 4,5), abacaxis da PI obtiveram notas acima deste limite até o $25^{\circ}$ dia, enquanto para os da PC, este limite foi ultrapassado no $20^{\circ}$ dia (Figura 6D), indicando um aumento em 5 dias na vida útil pós-colheita no armazenamento sob condições ambientes. Em conjunto, esses resultados indicam que os procedimentos adotados no sistema de PI para abacaxi, possivelmente, influenciaram na resistência e sanidade, resultando em frutas com melhor qualidade, como também reportado para caju de mesa por Andrade et al. (2008). 

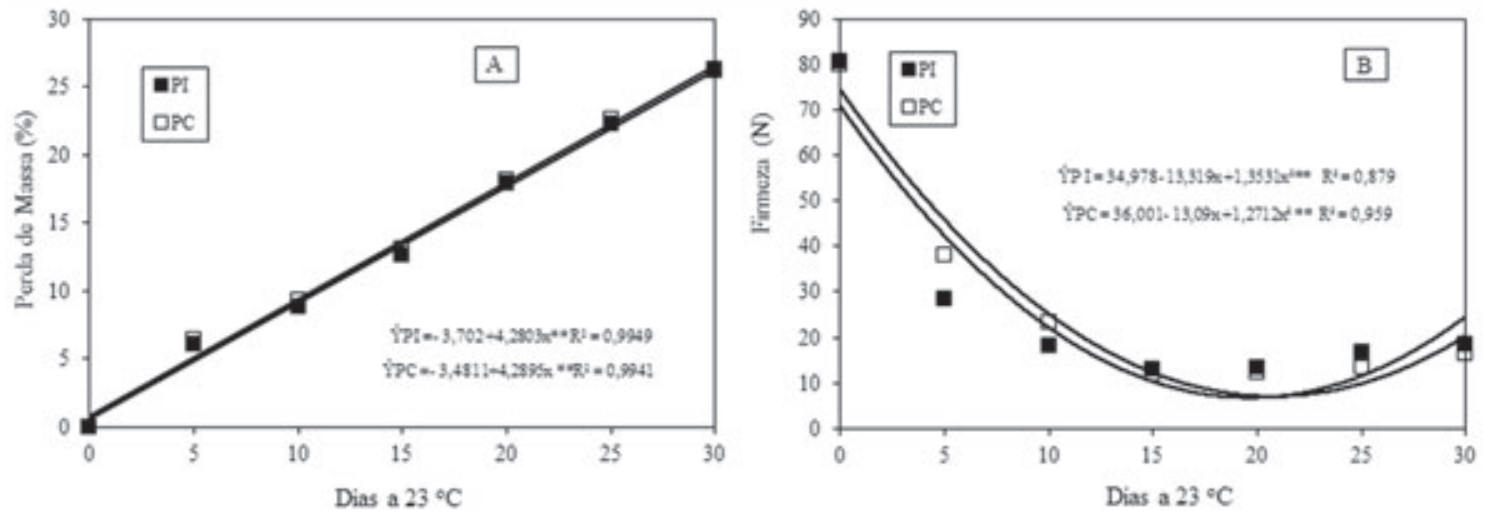

FIGURA 1 - Perda de massa (A) e firmeza (B) de abacaxi 'Perola' produzido nos sistemas de produção integrada (PI) e convencional (PC), e armazenado a $23 \pm 2{ }^{\circ} \mathrm{C}, 65 \pm 5 \%$ UR, por 30 dias, Santa Rita.
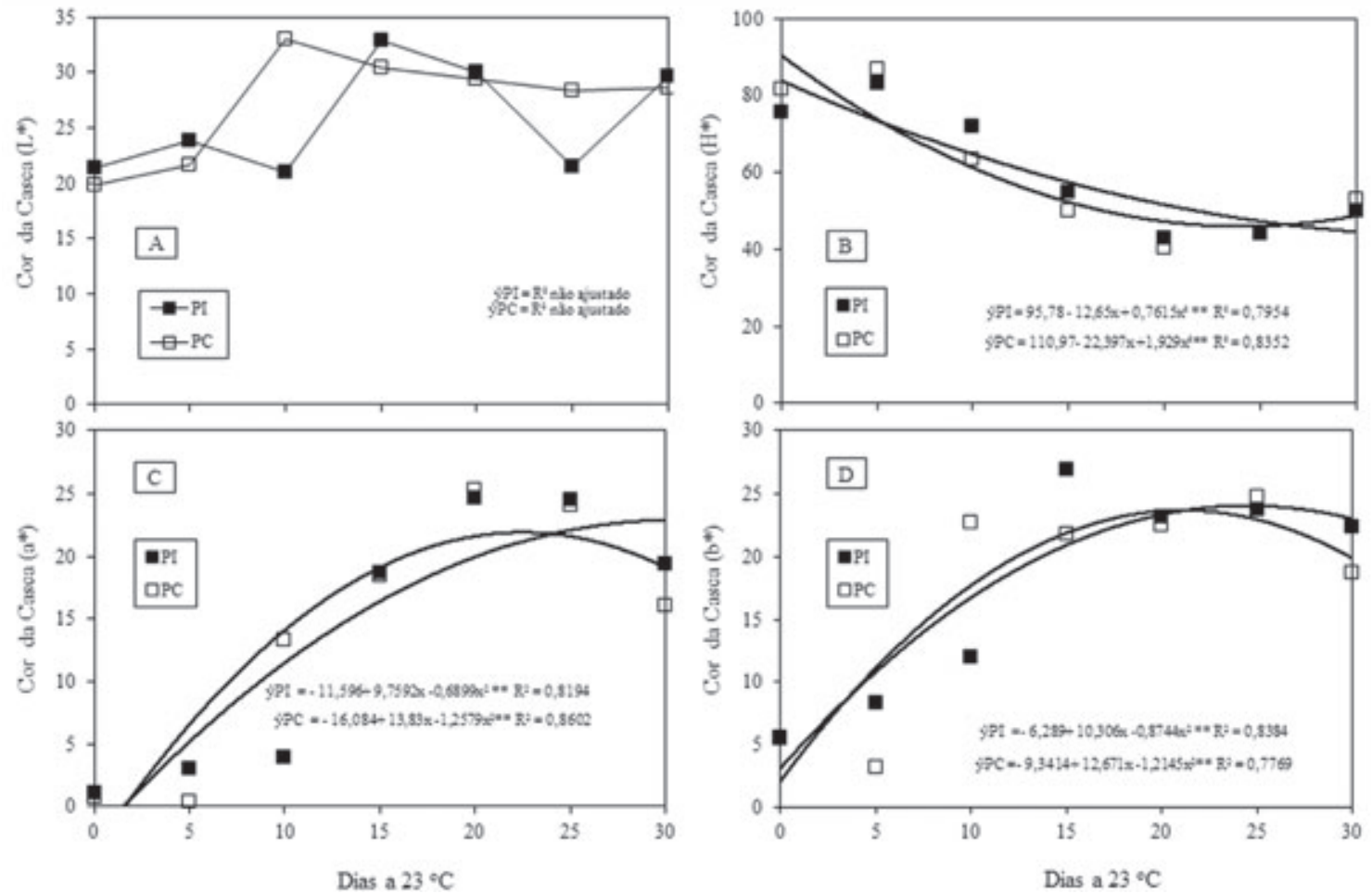

FIGURA 2- Cor da casca em L* (A), e a* (B), b* (C) e H* (D) de abacaxi ‘Perola' produzido nos sistemas de produção integrada (PI) e convencional (PC), e armazenado a $23 \pm 2{ }^{\circ} \mathrm{C}, 65 \pm 5 \%$ UR,por 30 dias, Santa Rita. 

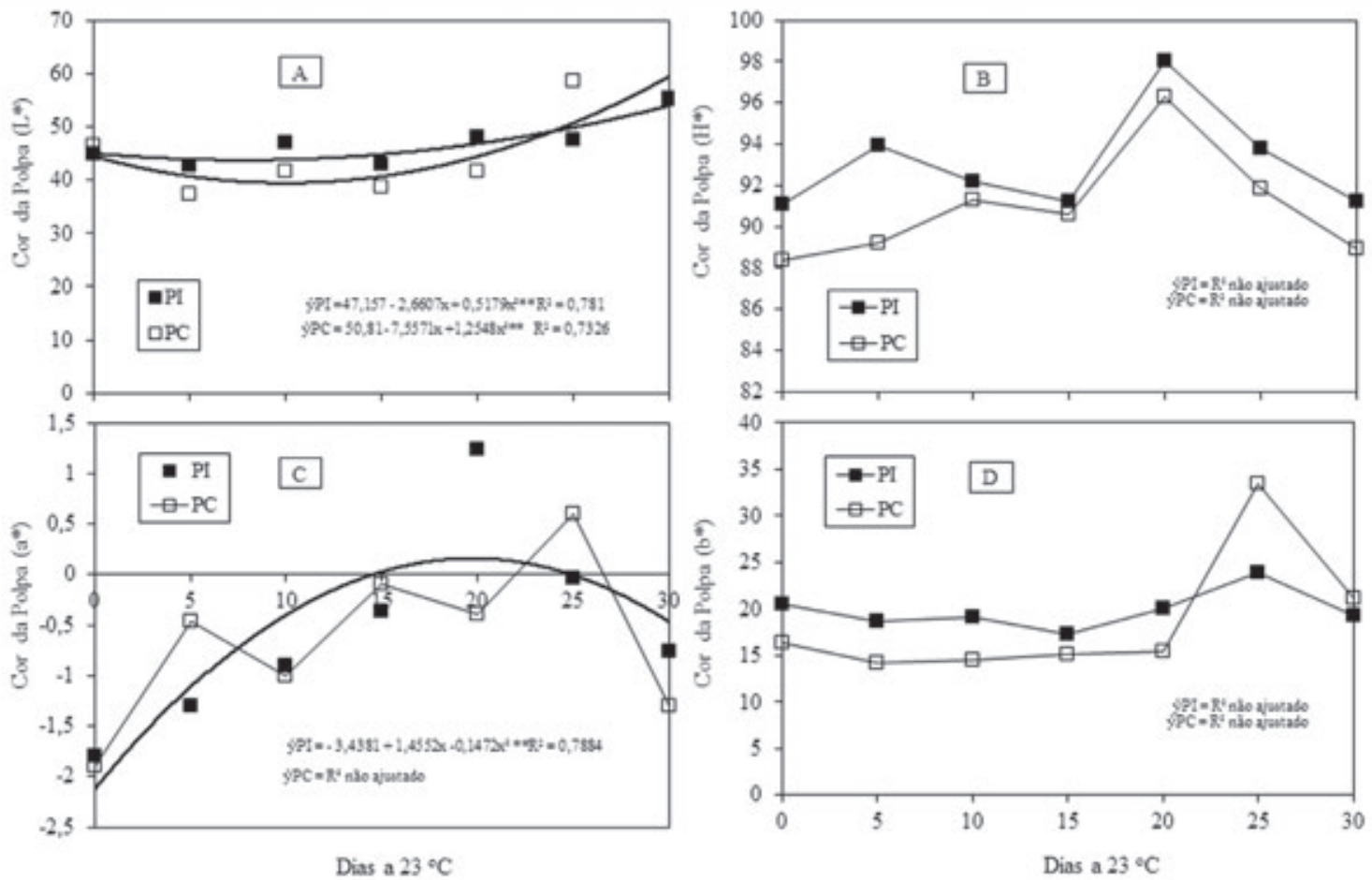

FIGURA 3 - Cor da polpa em L* (A), e a* (B), b* (C) e H* (D) de abacaxi ‘Perola' produzido nos sistemas de produção integrada (PI) e convencional (PC), e armazenado a $23 \pm 2{ }^{\circ} \mathrm{C}, 65 \pm 5 \%$ UR, por 30 dias, Santa Rita-PB.
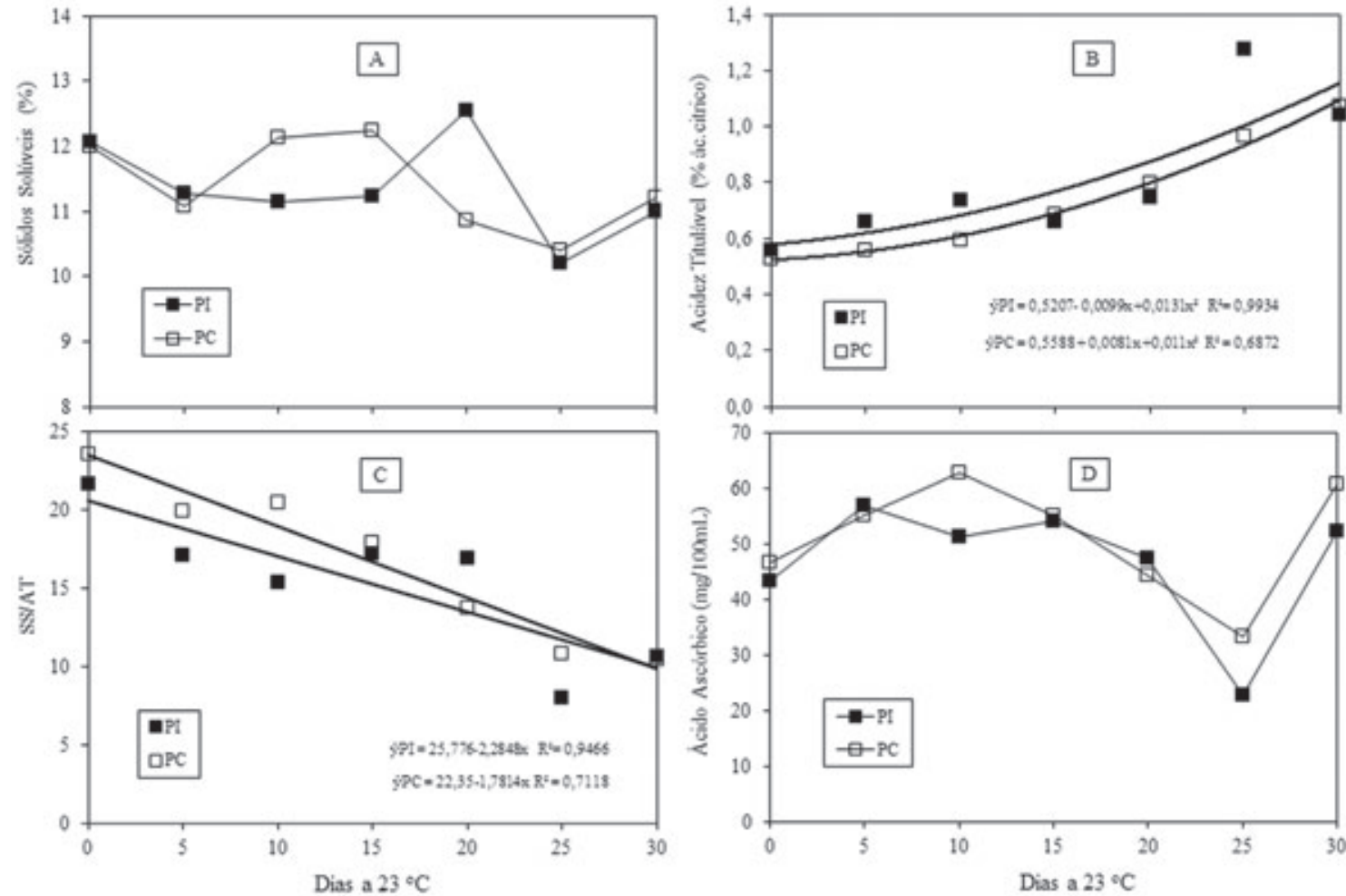

FIGURA 4 - Sólidos solúveis (A), acidez titulável (B), SS/AT (C) e ácido ascórbico (D) de abacaxi ‘Perola’ produzido nos sistemas de produção integrada (PI) e convencional (PC), e armazenado a 23 \pm 2 ${ }^{\circ} \mathrm{C}, 65 \pm 5 \%$ UR, por 30 dias, Santa Rita-PB. 

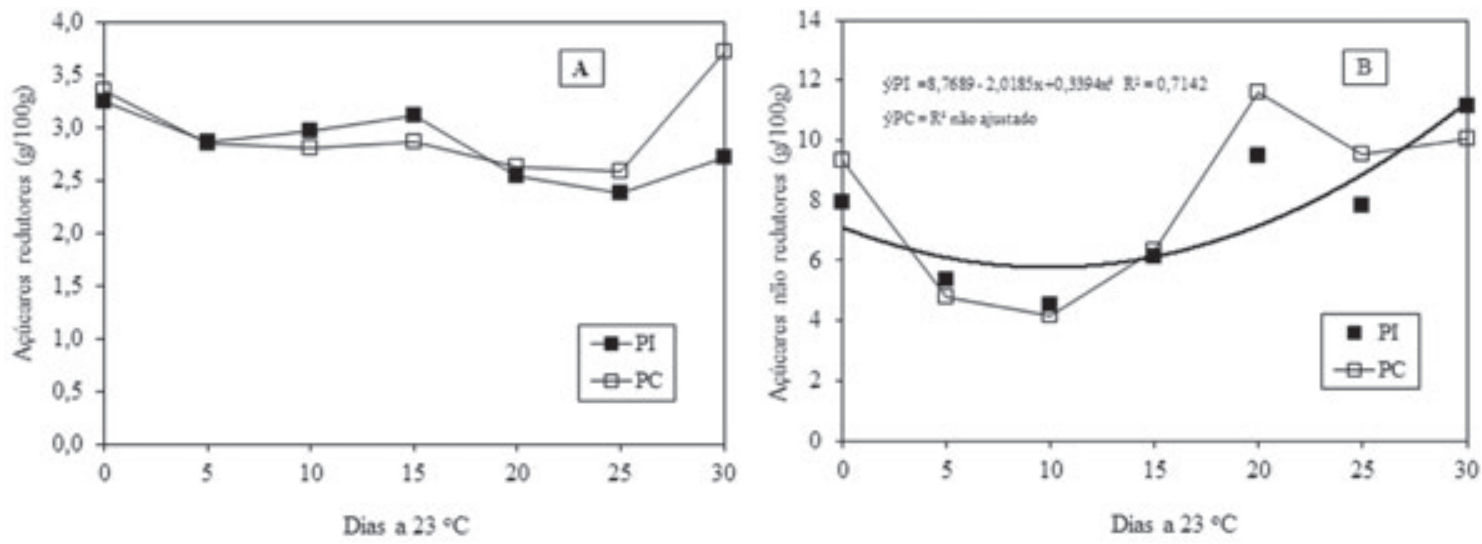

FIGURA 5 - Açúcares redutores (A), não redutores (B) de abacaxi 'Perola' produzido nos sistemas de produção integrada (PI) e convencional (PC), e armazenado a $23 \pm 2{ }^{\circ} \mathrm{C}, 65 \pm 5 \%$ UR, por 30 dias, Santa Rita-PB.
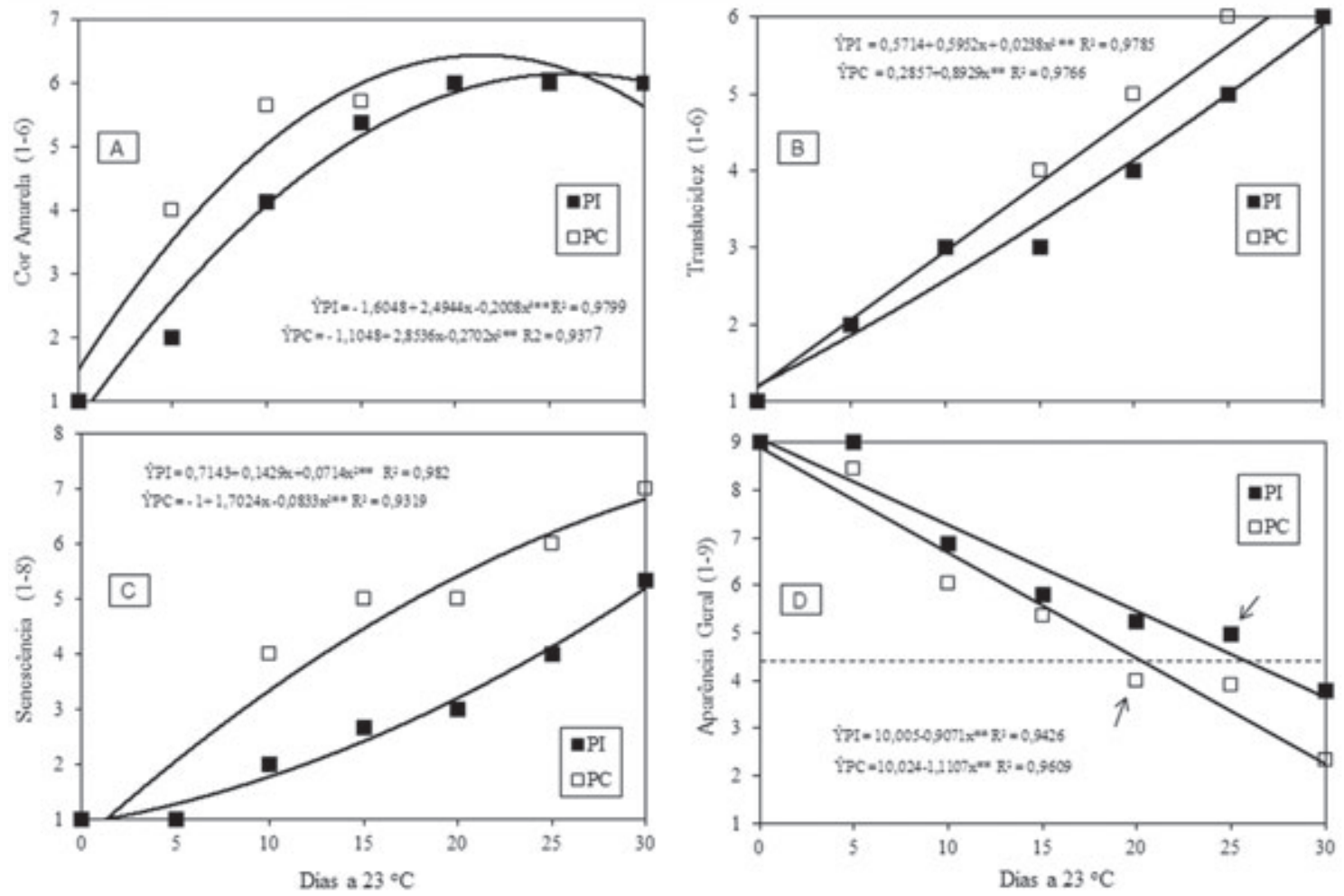

FIGURA 6 - Cor amarela da casca (A), translucidez (B), senescência (C) e aparência geral (D) de abacaxi 'Perola' produzido nos sistemas de produção integrada (PI) e convencional (PC), e armazenado a $23 \pm 2{ }^{\circ} \mathrm{C}, 65 \pm 5 \%$ UR, por 30 dias, Santa Rita-PB. 


\section{CONCLUSÕES}

O emprego do sistema de produção integrada no abacaxi 'Perola' resulta em frutos com retardo no desenvolvimento da cor amarela, menor translucidez, melhor aparência, menor índice de frutos senescentes e uma vida útil pós-colheita de 25 dias, com 5 dias de aumento de vida útil com relação a frutos do sistema convencional no armazenamento sob condições ambientes.

\section{AGRADECIMENTOS}

Ao BNB, MAPA e CNPq, pelo auxílio financeiro, e á CAPES, pela Bolsa ao primeiro autor.

\section{REFERÊNCIAS}

ANDRADE, A.P.S.; OLIVEIRA, V.H.; INNECCO, R.; SILVA, E.O. Qualidade de cajus de mesa obtidos nos sistemas de produção integrada e convencional. Revista Brasileira de Fruticultura, Jaboticabal, v.30, n.1, p.176-179, 2008.

AOAC - Association of Official Analytical Chemistry. Official methods of analysis of the Association of Official Analytical Chemistry. $17^{\text {th }}$ ed. Washington: AOAC, 2005. 1115p.

BECKER, W.F; MUELLER, S.; SANTOS, J.P; WAMSER ,A.F; SUZUKI, A; MARCUZZO, L.L. Viability of a prediction system for tomato late blight in the integrated production of tomato in Caçador, Brazil. Horticultura Brasileira, Brasília, v. 29, p. 520-525, 2011.

CARVAlHO, D. C. Composição, Colheita, Embalagem e Transporte do Fruto. In: CUNHA, G. A. P. da; CABRAL, J. R. S.; SOUZA L. F. S. O abacaxizeiro: cultivo, agroindústria e economia. Brasília: Embrapa Comunicação para Transferência de Tecnologia, 1999. 480 p.

CEAGESP. Programa brasileiro para a modernização da horticultura: normas de classificação do abacaxi. São Paulo: Centro de Qualidade em Horticultura-CQH/CEAGESP, 2003. (Documentos, 24).

CHEVRIN, C. Production raisonèe: defits dans le plantechologiques et commercial. Fruits, Paris, v.53, n.4, p.324-333, 2002.
CHITARRA, M. I.; CHITARRA, A. B. Pós-colheita de frutos e hortaliças: fisiologia e manuseio. 2.ed. Lavras: UFLA, 2005. 785p.

CUNHA, G. A .P. da. Paraíba e Bahia aderem à produção integrada de abacaxi, 2006. Disponível em: < www.agrosolution.com.br>. Acesso em: 30 abr.2012.

DANTAS Jr., O.R.; SILVA, S.M.; ALVES, R.E.; SILVA, E. O. Suscetibilidade a dano pelo frio em abacaxi 'Pérola' tratado com 1-metilciclopropeno. Revista Brasileira de Fruticultura, Jaboticabal, v.31, n.1, p.134-144, 2009.

FORNAZIER, A.; WAQUIL, P.D. A importância das organizações de interesse privado no agronegócio: o caso da cadeia produtiva da maçã no Brasil. Organizações Rurais \& Agroindustriais, Lavras, v. 14, n. 1, p. 46-59, 2012.

FRUTAS DOCE MEL. Especial abacaxi. João Pessoa: Frutas Doce Mel. 2009.Disponível em: < http://www.frutasdocemel.com.br/br/fruitnews. php?id=28. $>$ Acesso em: 18 maio 2012.

IAL- Instituto Adolfo Lutz. Métodos físicoquímicos para análise de alimentos. 4. ed. São Paulo, 2005, 783p.

IBGE. Levantamento sistemático da produção agrícola. Rio de Janeiro: LSPA, 2012. Disponível em: <http://www.sidra.ibge.gov.br/cgi-bin/prtabl.> Acesso em: 15 maio 2012.

MATTOS, L.M.; MORETTI, C.L.; MOURA, M.A. et al. Produção segura e rastreabilidade de hortaliças. Horticultura Brasileira, Brasília, v. 27, n. 4, p.408413, 2009.

PALIYATH, G.; MURR, D.P.; HANDA, A.K.; LURIE, S. Postharvest biology and technology of fruit, vegetables, and flowers. Ames: WileyBlackwell, 2008. 497 p.

PAULL, R. E.; CHEN, C.-C. Postharvest physiology, handling and storage of pineapple. In: BARTHOLOMEW, D.P., PAULL, R.E., ROHRBACH, K.G. The pineapple: botany, production and uses. Honolulu: CABI Publishing, 2003. p- 253-280. 
PIA-NORMAS DE PRODUÇÃO INTEGRADA ABACAXI. Embrapa/MAPA, 2008. 59p.

RODRIGUES, A.A.; MENDONÇA, R.M.N.; SILVA, A.P.; SILVA, S.M.; PEREIRA, W.E. Desenvolvimento vegetativo de abacaxizeiros 'Pérola' e 'Smooth Cayenne’ no Estado da Paraíba. Revista Brasileira de Fruticultura, Jaboticabal, v.32, n.1, p.126-134, 2010.

SANTOS, A.F. dos. Desenvolvimento e maturação de abacaxi e processamento mínimo de infrutescências colhidas sob boas práticas agrícolas e tratadas com 1-MCP. 2006. 224f. Tese (Doutorado em Agronomia) - Universidade Federal da Paraíba, Areia, 2006.
SEIBERT, E.; CASALI, M.E.: LEÃO, M.L.; et al. Postharvest quality of peaches harvested from integrated and conventional production systems. Pesquisa Agropecuária Brasileira, Brasília, v.42, n.6, p.793-801, 2007.

SILVA, S.J.P.; KOHLS, V.K.; MANICA-BERTO, R.; RIGATTO, P.; ROMBALDI, C.V. Apropriação tecnológica da produção integrada de pêssegos na região de Pelotas no Estado do Rio Grande do Sul. Ciência Rural, Santa Maria, v. 41, n.9, p. 1.6671.673, 2011.

SILVA, S.M.; COSTA, J.P.; MENDONÇA, R.M.N.; DANTAS, R.E.; SANTOS, A.F.; ASSU, R.T.; ALVES, R.E. Microbial Quality of Minimally Processed 'Perola' Pineapple Grown under Good Agricultural Practices System. Acta Horticulturae, The Hague, v. 864, p.379-386, 2010. 